\title{
MEMBANGUN KINERJA PEMASARAN MELALUI MARKETING KNOWLEDGE COMPETENCE DAN MARKETING NETWORKING
}

\author{
Hasyim \\ Dosen Fakultas Ekonomi Universitas Negeri Medan
}

\begin{abstract}
This research is done based on research result differences ( research gap) and differences of discussion focus about orientation of entrepreneurial and influence of knowledge interest and also company capability to marketing performance. Besides, there are also research problem about tightening of emulation in hand made clothes industry specially at small scale industry in Semarang city which's owning local market so that push brooding company to be more ahead in formulating strategy to improving its performance. Some condition and factor above were importance to be checked empirically and analyzed. Therefore the practitioner / owner in hand made clothes industry can obtain fact to support their exist in market, so the formulated strategy earn more accurate. This research is done by taking research object at small scale hand made clothes industry in Semarang, amounting to 170 company with its population element that is manager / owner. Sampling technique that used is purposive sampling. Amount of determined responder as research sample is 100 people. Analysis technique that used to interpret and analyze data in this research is technique of Structural Equation Model (SEM) of software package of AMOS. Result of examination proven hypothesis that factor entrepreneurial orientation and knowledge of market become positive effect of marketing capability and marketing performance. It is mean high significance of each other variables. As for model which is raised in this research can be accepted posed at by index according to where value of GFI 0,900, value of chi-square 87,987, probability value 0,084, value of TLI 0,965 and value of CFI 0,973, all have up to standard although value of AGFI 0,853 accepted by marginal.
\end{abstract}

Keywords : Entrepreneurial Orientation, Marketing Knowledge Competence, Marketing Capability, Marketing Networking, Performance

\section{PENDAHULUAN}

Pada dasa warsa terakhir ini telah terjadi prgeseran paradikma persaingan bisnis, dari persaingan antar perusahaan menjadi persaingan antar jaringan. Konsep kemitraan dalam suatu jejaring bisnis menjadi isu yang menarik dalam kondisi persaingan yang semakin kompetitif. Penekanan konsep ini adalah integrasi aliran informasi maupun material melalui jejaring bisnis untuk mendukung proses inovasi perusahaan yang merupakan suatu hal penting untuk mencapai peningkatan kapabilitas dan kinerja perusahaan dalam memenuhi kebutuhan dan keinginan konsumen (Lee\&Whang, 2000). Untuk meningkatkan kemitraan melalui program Connect and Develop.yaitu peningkatan produktivitas penelitian dan pengembangan $(R \& D)$ hingga (Hamm, 2007).

Kewirausahan adalah proses melakukan sesuatu yang baru dan atau berbeda untuk menciptakan kesejahteraan bagi dirinya sendiri dan nilai tambah bagi masyarakat (Kao,Kao\& Kao, 2002).Kewirausahaan telah menawarkan tiga landasan dimensi dari kecenderungan organisasional 
untuk proses manajemen kewirausahaan, yakni kemampuan inovasi, kemampuan mengambil risiko, dan sifat proaktif (Matsuno, Mentzer \& Ozsomer, 2002,p.35). Keunggulan dalam persaingan dan pengakuan dari pelanggan secara eksplisit telah menjadi bagian yang tidak terpisahkan (Weerawardena, 2003,p.411). Inovasi sebagai sebuah manifestasi kreatifitas dan kapabilitas pemasaran yang tidak selamanya identik atau serta merta menghasilkan kinerja / pengakuan pelanggan yang optimal sudah tentu membutuhkan penelitian yang lebih mendalam. Namun secara umum, orientasi kewirausahaan telah terbukti sukses meningkatkan kapabilitas pemasaran (Weerawardena, 2002,p.412).

Perhatian terhadap jaringan ini didukung oleh gagasan bahwa perusahaan tidak bisa bertahan dan berkembang hanya melalui masingmasing usaha, dan kinerja masingmasing perusahaan tergantung pada kegiatan dan kinerja orang lain . Oleh karena itu , sifat dan kualitas hubungan langsung dan tidak langsung perusahaan berkembang dengan mitra-mitranya ( Batt dan Pembelian , 2004) adalah mendasar untuk mengelola di kompleksitas jejaring. Dengan asumsi bahwa hubungan dan jaringan dianggap sumber daya sendiri, maka hubungan dan pendekatan jaringan untuk strategi memiliki sesuatu yang sama dengan RBV , bahwa sumber daya saat ini dari perusahaan yang dianggap sebagai faktor kunci dalam menentukan perilaku strategis perusahaan . Sementara RBV berfokus pada tiga kategori utama sumber daya, hubungan dan jaringan pendekatan mengidentifikasi portofolio perusahaan dari hubungan dan jaringan sumber daya posisi sebagai faktor kunci dalam perumusan strategi ( Ford dan Hakansson , 2006; Foss , 1999 ). Literatur jaringan tampaknya termasuk pandangan secara signifikan lebih luas sumber daya dan dari konteks di mana mereka dianggap .

Perusahaan yang kurang jeli akan menghadapi berbagai permasalahan, sehingga dengan alasan inilah diperlukan kreativitas manajemen dengan program-program pemasaran untuk dapat terus bertahan dalam dunia bisnis. Perubahan yang sedemikian cepat tanpa disadari telah mendorong banyak pihak (manajemen) untuk menghasilkan produk-produk baru yang bertujuan menarik minat pelanggan karena ada persaingan yang ketat di antara perusahaan (Andrews dan Smith, 1996).Pengembangan ide atau gagasan yang unik tentunya membutuhkan kompetensi dan kapabilitas dalam pemasaran, agar kinerja pemasaran dapat dihasilkan secara optimal.

Oleh karena itu, penelitian ini akan mencoba membahas beberapa temuan dan implikasi penelitian terdahulu dan fenomena bisnis yang terjadi di industri pakaian jadi, di mana variabel orientasi kewirausahaan, kompetensi pengetahuan pemasaran, dan kapabilitas pemasaran menjadi faktor pendukung upaya-upaya perusahaan mencapai kinerja pemasaran yang optimal dan berkelanjutan.

\section{KAJIAN PUSTAKA}

Market Sensing

Penginseraan Pasar adalah kemampuan perusahaan memahami 
JURNAL PLANS

Penelitian Ilmu Manajemen \& Bisnis

ISSN: $1978-7057$

E-ISSN: 2527-306X

keadaan pasar, keinginan pelangan, keinginan saluran distribusi, meahami tingkat persaingan pasar.yang dijadikan dasar, kiat dan sumber daya untuk mencari peluang menuju kesuksesan. Beberapa literatur manajemen memberikan tiga landasan dimensi-dimensi dari kecenderungan organisasional untuk proses manajemen Market sensing, yakni kemampuan inovasi, kemampuan mengambil risiko, dan sifat proaktif (Weerawardeena, 2003,p.411; Matsuno, Mentzer dan Ozsomer, 2002).

Penginderaan pasar dikenal sebagai pendekatan baru dalam pembaruan kinerja perusahaan.Hal ini, tentu harus direspon secara positif oleh perusahaan yang mulai mencoba bangkit dari keterpurukan ekonomi akibat krisis

berkepanjangan.Kewirausahaan

disebut-sebut sebagai spearhead (pelopor) untuk mewujudkan pertumbuhan ekonomi perusahaan berkelanjutan dan berdaya saing tinggi. Membangun kewirausahaan dinyatakan sebagai satu dari empat pilar dalam memperkuat lapangan pekerjaan.Orang yang melakukan wirausaha dinamakan wirausahawan.Bentuk dari aplikasi atas sikap-sikap kewirausahaandapat diindikasikan dengan orientasi kewirausahaan dengan indikasi kemampuan inovasi, proatifitas, dan kemampuan mengambil resiko (Looy et al. 2003).

Kemampuan inovasi berhubungan dengan persepsi dan aktivitas terhadap aktivitas-aktivitas bisnis yang baru dan unik (Schumpeter dan Milton, 1989).Kemampuan berinovasi adalah titik penting dari kewirausahaan dan esensi dari karakteristik kewirausahaan. Beberapa hasil penelitian dan literatur kewirausahaan menunjukkan bahwa orientasi kewirausahaan lebih signifikan mempunyai kemampuan inovasi daripada yang tidak memiliki kemampuan dalam kewirausahaan (Koh, 1997,p.9).

Proaktifitas seseorang untuk berusaha berprestasi merupakan petunjuk lain dari aplikasi atas orientasi kewirausahaan secara pribadi. Demikian pula bila suatu perusahaan menekankan proaktifitas dalam kegiatan bisnisnya, maka perusahaan tersebut telah melakukan aktifitas kewirausahaan yang akan secara otomatis mendorong tinginya kinerja (Weerawardena, 2003,424). Perusahaan dengan aktifitas kewirausahaan yang tinggi berarti tampak dari tingginya semangat yang tidak pernah padam karena hambatan, rintangan, dan tantangan.Sikap aktif dan dinamis adalah kata kuncinya.(Doukakis, 2002).

Seseorang yang berani mengambil risiko dapat didefinisikan sebagai seseorang yang berorientasi pada peluang dalam ketidakpastian konteks pengambilan keputusan.Hambatan risiko merupakan faktor kunci yang membedakan perusahaan dengan jiwa wirausaha dan tidak. Fungsi utama dari tingginya orientasi kewirausahaan adalah bagaimana melibatkan pengukuran risiko dan pengambilan risiko secara optimal (Looy et al. 2003).

Penelitian ini mengadopsi indikator variabel orientasi kewirausahaan, yaitu: kemampuan berinovasi, proaktitas, dan keberanian dalam mengambil risiko seperti yang 
telah digunakan dalam penelitian Weerawardena (2003).

\section{Kompetensi Pengetahuan Pemasaran}

Manajemen pengetahuan pemasaran adalah sekumpulan proses yang menciptakan, memisahkan dan menyimpan pengetahuan tentang pelanggan dan pilihannya, pesaing, produk, saluran distribusi dan tren (Sinkula,1994,p.39). Kapabilitas pemasaran dibangun ketika pemasar secara berulang menerapkan keterampilan dan pengetahuan pemasaran mereka guna mendukung keputusan dan kegiatan perusahaan. Kapabilitas pemasaran perusahaan meningkat ketika pemasar menerapkan pengetahuan pemasaran dalam memecahkan permasalahan(Slater dan Narver, 1995, p.71). Kompetensi pengetahuan pasar menjadi kunci bagi kompetensi organisasi (Hamel dan Prahalad, 1994; Sinkula 1994).Glazer (1991) menganggap pengetahuan pemasaran sebagai aset strategis perusahaan.Artinya pengetahuan pemasaran menjadi salah satu aset berharga bagi bisnis dan menyediakan keunggulan kompetitif bagi bisnis, hasilnya memberikan kinerja bisnis yang unggul.

Jika marketing know-how lebih pada aspek prosedural, maka manajemen pengetahuan lebih mengarah pada pengertian kondisi deklaratif (Nonaka, 1994).Pengetahuan deklaratif sendiri, lebih fokus pada pernyataan fakta ataupun informasi, sedangkan pengetahuan prosedural lebih digambarkan sebagai mengetahui bagaimana mengerjakan sesuatu. Istilah manajemen pengetahuan pemasaran mengarah pada perpindahan, penyebaran, dan penyimpanan pengetahuan pemasaran (Darroch, 2003,p.577).

\section{Kapabilitas Pemasaran}

Kapabilitas pemasaran dapat diartikan sebagai proses terintegrasi yang dirancang untuk menerapkan kumpulan pengetahuan, keterampilan dan sumberdaya dari perusahaan bagi usaha yang terkait dengan kebutuhan yang terkait dengan pasar. Kapabilitas pemasaran memungkinkan bisnis memberikan nilai tambah dan menciptakan nilai bagi pelanggan serta menjadi kompetitif. Menurut sudut pandang berbasis sumber daya, keunggulan kompetitif dapat dicapai melalui kepemilikan aset penting atau kapabilitas (Barney, 1991,p.101).Perusahaan secara potensial memiliki akses pada kapabilitas pemasaran yang berbeda (Day,1994,p.49). Studi Fahy et al (2000,p.65) hanya mengkhususkan diskusi pada tiga kunci kapabilitas pemasaran yaitu : orientasi pasar (marketing orientation (MO)); batas waktu (time horizon) dalam pengambilan keputusan strategis dalam perusahaan; dan positioning dari kapabilitas perusahaan. Weber (1992) menggolongkan 2 kriteria pertama sebagai bagian dari penggambaran kondisi tingkat perusahaan (corporate level) atau kapabilitas secara keseluruhan (overall capabilities); dan kriteria terakhir sebagai kapabilitas unit bisnis, yang ketiganya menuntun dan mempengaruhi tindakan pemasaran sebuah perusahaan.

Kapabilitas untuk mengadopsi batas strategis dioperasionalisasikan 
dengan menggunakan 3 (tiga) konstruk yaitu apakah tujuan utama organisasi adalah untuk bertahan ; memperoleh keuntungan jangka pendek; atau membangun posisi pasar dalam jangka panjang. Pada akhirnya kapabilitas dalam membangun posisi pasar agar dapat bertahan dilihat sebagai elemen kunci dalam kegiatan pemasaran perusahaan (Hooley and Saunders 1993; Porter 1996; Ries and Trout 1982.Ada tiga posisi yang seharusnya diperoleh, yaitu kualitas produk yang lebih baik dibandingkan dengan pesaing; kualitas layanan yang lebih baik dibandingkan dengan pesaing; kualitas harga yang lebih kompetitif dibandingkan dengan pesaing (Holey, Beracs, \& Kolos, 1993).

\section{Kinerja Pemasaran}

Pengukuran kinerja dalam penelitian bidang bisnis dan pemasaran terus berkembang dengan dasar indikasi yang bervariasi. Gambaran kinerja absolut seperti ROI, volume penjualan, dan bagian pasar (marketshare) relatif sulit untuk dapat diperbandingkan antar perusahaan dengan kondisi ukuran perusahaan yang berbeda, wilayah operasi pasar yang berbeda, penggunaan standar akuntansi yang berbeda, dan penentuan pasar yang juga memiliki banyak perbedaan. Kemudian, masih banyak pula perdebatan bahwa strategi-strategi baru dan kenyataan persaingan telah bergeser dari konsep kepercayaan pada pengukuran berbasis

keuangan, menjadi indikasiindikasi basis non keuangan seperti variabel kualitas, efektivitas manufaktur, inovasi dan kepuasan pelanggan (Eccles 1991; Kaplan and
Norton 1992).Namun bagaimanapun, pengukuran profitabilitas absolut tetap memiliki kelemahan konseptual, metodelogis, dan kelemahan praktis (Doyle 1994).

Konsep yang lebih sederhana dan praktis juga dijelaskan Ferdinand (2002) yang menyatakan bahwa kinerja pemasaran yang baik dinyatakan dalam tiga besaran utama yaitu: pertumbuhan pelanggan, pertumbuhan penjualan, dan porsi pasar, yang pada akhirnya bermuara pada keuntungan perusahaan.

Oleh karenanya, penelitian ini menggunakan pengukuran kinerja relatif dan mengkombinasikan ukuran kinerja berbasis finansial dan berbasis-pasar (market-based performance). Bentuk implementasinya, 4 indikator digunakan, yakni: pertumbuhan penjualan, pertumbuhan pasar, porsi pasar, dan kemampulabaan.

\section{Telaah Hubungan Kausalitas antar Variabel \\ Orientasi Kewirausahaan dan \\ Kapabilitas Pemasaran}

Kewirausahaan adalah faktor kunci dalam mendeterminasikan aktifitas pembangunan kapabilitas perusahaan. Orientasi kewirausahaan dari suatu perusahaan akan mendorong orientasi kompetitifnya (Merz \& Suber, 1995). Kewirausahan juga merupakan elemen kunci dalam mendapatkan keunggulan bersaing yang tentu saja juga akan berakibat positif pada kinerja finansialnya. Perusahaan dengan kemampuan wirausaha yang tinggi akan sangat memperhatikan inovasi, inisiasi perubahan, dan kecepatan respon yang tinggi untuk terus berubah 
secara fleksibel (Naman \& Slevin, 1993).

Orientasi kewirausahaan dalam penelitian ini merupakan bentuk perilaku di mana atau bagaimana perusahaan menunjukkan inovasinya, proaktifitas, dan keberaniannya mengambil resiko dalam keputusankeputusan strategisnya. Izzoni (1991) telah menunjukkan tingginya keeratan hubungan di antara orientasi kewirausahaan, kapabilitas perusahaan, dan inovasi. Menurutnya, Strategi berbasis inovasi akan mengakumulasi kapabilitas spesifik yang akan membedakannya dengan pesaing-pesaing dan mempunyai kemampuan yang cukup untuk menghadapi lingkungan yang berbeda-beda.Aktifitas fundamental dari kewirausahaan tidak hanya dengan menciptakan produk-produk yang lebih unggul dibandingkan pesaing, namun juga unggul dan mendapatkan pengakuan dari pelanggan karena secara eksplisit memang telah menjadi bagian dari kebutuhannya (Weerawardena, 2003,p.422).

Dari uraian di atas, maka hipotesis yang dapat dirumuskan adalah sebagai berikut: $H 1$ : Orientasi Kewirausahaan berpengaruh positif terhadap kapabilitas pemasaran

\section{Kompetensi Pengetahuan Pemasaran dan Kapabilitas Pemasaran}

Menurut Menon et al (1999), aset dan kapabilitas pemasaran merupakan bagian dalam proses marketing strategy making. Kapabilitas pemasaran dibangun ketika pemasar secara berulang menerapkan keterampilan dan pengetahuan pemasaran mereka guna mendukung keputusan dan kegiatan perusahaan.Kapabilitas pemasaran perusahaan meningkat ketika pemasar menerapkan pengetahuan pemasaran dalam memecahkan permasalahan (Slater dan Narver, 1995).

Temuan Slater dan Narver (1995) di atas selaras dengan temuan Tsai \& Shih (2004) yang menyatakan hubungan kausalitas yang selaras di antara kedua variabel tersebut. Kompetensi pengetahuan pemasaran merupakan hasil dari proses pembelajaran orgaisasional. Ini karena salah satu sasaran organisasi adalah membentuk akumulasi kompetensi sebagai hasil pembelajaran organisasional yang berkesinambungan (Ferdinand, 2002).Prosesnya adalah dengan mengembangkan kebiasaan menelaah situasi, merinci situasi organisasi, dan menyatakannya dalam acuan-acuan strategi yang dapat diikuti.Elemenelemen bauran pemasaran sendiri merupakan indikasi dari kapabilitas pemasaran, menurut Tsai \& Shih (2004).

Dari uraian di atas, maka hipotesis yang dapat dirumuskan adalah sebagai berikut: $H 2$ : Kompetensi pengetahuan pasar berpengaruh posiif terhadap kapabilitas pemasaran

\section{Orientasi Kewirausahaan dan Kinerja Pemasaran}

Menurut Siguaw, Simpson, dan Baker (1998), kompetensi kewirausahaan dibutuhkan di dalam implementasi strategi pemasaran agar diperoleh keunggulan bersaing yang mantap melalui nilai responsifitas atas kebutuhan pelanggan. Sedangkan jiwa kewirausahaan sendiri meliputi 5 
hal, yakni: otonomi, keinovatifan, pengambilan resiko, proaktifitas, dan agresifitas kompetitif. Semuanya berujung pada pembukuan kinerja keuangan yang maksimal.

Yeoh \& Jeong (2000) secara lebih spesifik memberikan kesimpulan pada penelitiannya bahwa kewirausahaan akan memberikan efek positif pada kinerja ekspor melalui kinerja struktur saluran ekspor yang menjadi elemen penting strategi pemasaran. Temuan ini relevan dengan konsep Kotler (2001) yang menyatakan bahwa pemasaran entrepreneurial merupakan sebuah konsep yang terpadu di era penuh perubahan seperti sekarang ini. Hasil penelitian yang sedikit berbeda adalah temuan Barret (2000) yang menyatakan bahwa kewirausahaan korporat akan memberikan efek positif pada kinerja perusahaan di mana bauran pemasaran sebagai manifestasi taktik pemasaran dan petunjuk nyata kinerja pemasaran hanya merupakan faktor moderator. Ini berarti bahwa peran kinerja pemasaran hanya terbukti menjadi faktor pendukung dan bukan menjadi tujuan hasil.

Dari uraian di atas, maka hipotesis yang dapat dirumuskan adalah sebagai berikut: $H 3$ : Orientasi kewirausahaan berpengaruh positif terhadap kinerja pemasaran.

\section{Kompetensi Pengetahuan}

Pemasaran dan Kinerja Pemasaran Kompetensi pengetahuan pemasaran menjadi kunci bagi kompetensi organisasi (Hamel dan Prahalad, 1994; Sinkula 1994) dan sebagai hasil akhirnya adalah kinerja pemasaran yang signifikan.Oleh karena itu, kompetensi pengetahuan pemasaran merupakan aset yang sangat berharga dan potensial dalam upaya perusahaan meningkatkan keunggulan bersaing (Fahey \& Smithee, 1999).

Beberapa temuan peneiti di atas selaras dengan temuan studi yang dilakukan oleh Tsai \& Shih (2004) yang menyatakan bahwa perusahaan dapat meningkatkan kinerja pemasaran dengan membangun kompetensi dalam manajemen pengetahuan pemasaran melalui kapabilitas pemasaran. Manajemen pengetahuan pemasaran yang efektif membantu meningkatkan kapabilitas pemasaran yang pada akhirnya akan meningkatkan kinerja bisnis. Namun yang menjadi menarik, temuan Tsai \& Shih (2004) ini mensyaratkan pengaruh kompetensi pengetahuan pemasaran hanya berpengaruh positif terhadap kinerja pemasaran ketika melalui variabel kapabilitas pemasaran.Artinya efek langsung kompetensi pengetahuan pasar terhadap kinerja pemasaran tidak terbukti signifikan.

Dari uraian di atas, maka hipotesis yang dapat dirumuskan adalah sebagai berikut: H4 : Kompetensi pengetahuan pemasaran berpengaruh positif terhadap kinerja pemasaran

\section{Kapabilitas Pemasaran dan Kinerja Pemasaran}

Kinerja adalah kombinasi yang unik dari basis pengetahuan, sumber daya yang terlihat dan tidak terlihat dari perusahaan dan menunjukan apa yang dapat dicapai perusahaan melalui kumpulan sumber daya yang bekerja sama.(Hitt et al 1997). Kinerja adalah sekumpulan 
keterampilan dan pengetahuan, latihan melalui proses berorganisasi, yang memungkinkan perusahaan dalam mengkoordinasikan kegiatannya, menggunakan aset mereka, dan secara terus menerus belajar dan maju (Day, 1994,p.37).

Kapabilitas pemasaran yang unik dibangun ketika perusahaan memadukan pengetahuan khusus dan ketrampilan dengan sumberdaya terlihat dan tidak terlihat lainnya yang dimiliki. (Day, 1994,p.44). Karena kapabilitas pemasaran ini tidak dapat ditiru dan tidak tergantikan, dan tidak dapat secara mudah dipindahkan pada pesaing, kapabilitas ini menyediakan dasar bagi kemampuan kompetitif yang berkelanjutan. Day (1994) mencatat tidak mungkin untuk dapat menghitung seluruh kapabilitas pemasaran, karena pada dasarnya sangat bervariasi sesuai bisnis dan situasi persaingan, komitmen masa lalu, dan antisipasi keperluan masa depan. Kapabilitas pemasaran adalah sumber penting keunggulan kompetitif (Fahly et al, 2000).Song dan Pary (1997) menemukan fakta bahwa kapabilitas pemasaran mempengaruhi keunggulan kompetitif.Tambahan, Fahley et al (2000) menyatakan kapabilitas pemasaran meningkatkan kinerja keuangan dan kinerja pasar.

Dari uraian di atas, maka hipotesis yang dapat dirumuskan adalah sebagai berikut: $H 5$ : Kapabilitas Pemasaran berpengaruh positif terhadap kinerja pemasaran

\section{METODE PENELITIAN Populasi dan Sampel}

Populasi pada penelitian ini adalah perusahaan batik di Jawa tenggah yang berada pada skala kecil.dan Menengah Batasan Industri kecil adalah (revrisond 1998,p73) :

a. Omset dan Asset dibawah 600 juta, menurut BI. 300 juta, menurut Dept

Keuangan 100 juta, Mnrt UU

No. $9 / 1995$ max 200juta

b. Jumlah tenaker $5-19$ orang

c. Modal kurang dari 25 Juta

Adapun jenis produk yang dihasilkan meliputi keseluruhan jenis batik.Jumlah populasi menurut data Kantor Dinas Perindustrian dan Perdagangan Jawa Tenggah adalah sebanyak 2867 perusahaan.

Ukuran sampel minimum yang disarankan (Hair et al 1995, Ferdinand,2002,p.47) adalah sebanyak 5 observasi untuk setiap estimated parameter, dan ukuran sampel yang sesuai dan disarankan adalah antara 100-200. Dengan demikian, karena estimated parameter dalam penelitian ini ada 14, maka:Jumlah sample minimal = Jumlah estimated parameter $\times 5=$ $21 \times 5=105$ Jumlah tersebut merupakan jumlah minimal ukuran sampel yang disarankan oleh Hair et al (1995). Dan dalam penelitian ini akan digunakan sampel sebanyak 185 agar memenuhi syarat dalam penggunaan SEM sehingga sedapat mungkin diperoleh goodness-of-fit yang layak. Teknik sampling yang akan digunakan dalam penelitian ini adalah metode pemilihan sampel bertujuan (purposive sampling).

\section{Teknik Analisis}

Analisis data merupakan proses penyederhanaan data ke dalam bentuk yang lebih mudah untuk dibaca dan diinterpretasikan. Penelitian ini menggunakan model kausalitas atau hubungan pengaruh 
JURNAL PLANS

Penelitian Ilmu Manajemen \& Bisnis

ISSN: 1978-7057

E-ISSN: 2527-306X

untuk menguji hipotesis yang diajukan maka teknik analisis yang dipakai adalah SEM (Structural Equation Modelling). SEM adalah sekumpulan teknik-teknik statistikal yang memungkinkan pengujian sebuah rangkaian hubungan yang relatif rumit, secara simultan (Ferdinand, 2002). Digunakannya teknik analisis SEM dalam penelitian ini karena pada penelitian ini dibangun model yang memuat beberapa variabel independen dan beberapa variabel dependen. Teknik analisis SEM memungkinkan peneliti dapat menjawab pertanyaan penelitian yang bersifat regresif maupun dimensional yaitu mengukur

dimensi-dimensi yang terdapat dalam sebuah konsep (Ferdinand, 2002).

\section{HASIL PENELITIAN DAN PEMBAHASAN \\ Proses dan Hasil Analisis Data Pemilihan Matriks Input dan Teknik Estimasi}

Matriks input yang dapat digunakan adalah korelasi atau kovarians. Karena yang diuji adalah hubungan kausalitas, maka input yang lebih tepat digunakan dalam operasi SEM adalah kovarians (Ferdinand, 2002). Dari pengolahan data statistik deskriptif, kovarians data tersaji dalam tabel 1. di bawah ini.

Tabel 1. Sample Covarians-Estimates

\begin{tabular}{|l|c|c|c|c|c|c|c|c|c|c|c|c|c|c|}
\hline & $\mathbf{X 1 4}$ & $\mathbf{X 1 3}$ & $\mathbf{X 1 0}$ & $\mathbf{X 1 2}$ & $\mathbf{X I I}$ & $\mathbf{X I}$ & $\mathbf{X 2}$ & $\mathbf{X 3}$ & $\mathbf{X 7}$ & $\mathbf{X 8}$ & $\mathbf{X 9}$ & $\mathbf{X 4}$ & $\mathbf{X 5}$ & $\mathbf{X 6}$ \\
\hline $\mathrm{X} 1$ & 3.82 & 2.45 & 2.17 & 1.73 & 1.83 & 1.72 & 1.54 & 1.97 & 2.29 & 1.82 & 1.77 & 1.22 & 1.09 & 1.05 \\
\hline $\mathrm{X} 1$ & 2.45 & 3.39 & 1.78 & 1.54 & 1.76 & 1.89 & 1.30 & 1.81 & 1.8 & 1.38 & 1.15 & 1.51 & 1.07 & 1.35 \\
\hline $\mathrm{X} 1$ & 2.17 & 1.78 & 3.67 & 1.76 & 1.56 & 1.22 & 1.31 & 1.67 & 2.3 & 2.11 & 2.25 & 1.02 & 1.07 & 1.27 \\
\hline $\mathrm{X} 1$ & 1.73 & 1.54 & 1.76 & 2.98 & 1.61 & 1.25 & 1.01 & 1.66 & 1.80 & 1.43 & 1.18 & 1.31 & 1.00 & 0.90 \\
\hline $\mathrm{X} 11$ & 1.83 & 1.76 & 1.56 & 1.61 & 3.20 & 1.88 & 1.61 & 1.77 & 1.69 & 1.18 & 1.31 & 1.06 & 0.66 & 1.28 \\
\hline $\mathrm{XI}$ & 1.72 & 1.89 & 1.22 & 1.25 & 1.88 & 3.71 & 2.34 & 2.74 & 1.58 & 1.3 & 0.90 & 0.98 & 0.54 & 1.09 \\
\hline $\mathrm{X} 2$ & 1.54 & 1.30 & 1.31 & 1.01 & 1.61 & 2.34 & 3.31 & 2.58 & 1.55 & 1.25 & 1.27 & 0.91 & 0.54 & 0.69 \\
\hline $\mathrm{X} 3$ & 1.97 & 1.81 & 1.67 & 1.66 & 1.77 & 2.74 & 2.58 & 4.92 & 1.91 & 1.33 & 1.32 & 1.20 & 0.43 & 1.09 \\
\hline $\mathrm{X} 7$ & 2.29 & 1.8 & 2.3 & 1.80 & 1.69 & 1.58 & 1.55 & 1.91 & 4.40 & 2.12 & 1.75 & 0.77 & 0.46 & 1.15 \\
\hline $\mathrm{X} 8$ & 1.82 & 1.38 & 2.11 & 1.43 & 1.18 & 1.3 & 1.25 & 1.33 & 2.12 & 3.53 & 1.27 & 0.95 & 0.74 & 1.04 \\
\hline $\mathrm{X} 9$ & 1.77 & 1.15 & 2.25 & 1.18 & 1.31 & 0.90 & 1.27 & 1.32 & 1.75 & 1.27 & 3.48 & 0.98 & 0.72 & 1.04 \\
\hline $\mathrm{X} 4$ & 1.22 & 1.51 & 1.02 & 1.31 & 1.06 & 0.98 & 0.91 & 1.20 & 0.77 & 0.95 & 0.98 & 3.30 & 1.88 & 1.51 \\
\hline $\mathrm{X} 5$ & 1.09 & 1.07 & 1.07 & 1.00 & 0.66 & 0.54 & 0.54 & 0.43 & 0.46 & 0.74 & 0.72 & 1.88 & 3.55 & 2.42 \\
\hline $\mathrm{X} 6$ & 1.05 & 1.35 & 1.27 & 0.90 & 1.28 & 1.09 & 0.69 & 1.09 & 1.15 & 1.04 & 1.04 & 1.51 & 2.42 & 4.39 \\
\hline
\end{tabular}

Sumber: Data yang dianalisis dalam penelitian ini, 2013

Teknik estimasi yang digunakan dalam penelitian ini adalah maximum likelihood estimation method. Dan seperti yang telah dijelaskan di atas, Confirmatory Factor Analysis merupakan tahapan awal dalam analisis, kemudian Full Model of Structural Equation Modelling (SEM) menjadi tahapan utama yang menghasilkan temuan dalam analisis penelitian.

\section{Analisis Faktor Konfirmatori}

Analisis faktor konfirmatori akan menjelaskan pengukuran atas dimensi-dimensi yang membentuk variabel laten dalam model penelitian. Variabel laten yangdigunakan dalam penelitian ini terdiri dari 4 unobserved variabel dan 14 observed variable sebagai dimensi pembentuknya. Tujuan dari analisis faktor konfirmatori adalah untuk menguji unidimensionalitas 
JURNAL PLANS

Penelitian Ilmu Manajemen \& Bisnis

ISSN: $1978-7057$

E-ISSN: 2527-306X

dari dimensi-dimensi pembentuk masing-masing variabel laten.

Tabel 2. Hasil Pengujian Kelayakan Model

Pada Analisis Faktor Konfirmatori Variabel-Variabel Eksogen

\begin{tabular}{|c|c|c|c|}
\hline Goodness of Fit Index & Cut of Value & \multicolumn{1}{c|}{ Hasil Olah Data } & Evaluasi Model \\
\hline Chi-Square & 15,507 & 13,241 & Baik \\
Probability & $>0,05$ & 0,104 & Baik \\
GFI & $>0,90$ & 0,962 & Baik \\
AGFI & $>0,90$ & 0,899 & Marjinal \\
TLI & $>0,95$ & 0,954 & Baik \\
CFI & $>0,95$ & 0,975 & Baik \\
CMIN/DF & $<2,00$ & 1,665 & Baik \\
RMSEA & $<0,08$ & 0,081 & Marjinal \\
\hline
\end{tabular}

Untuk uji statistik, hubungan antar variabel yang menjadi dasar dalam hipotesis penelitian telah diajukan.Uji statistik hasil pengolahan dengan SEM dilakukan dengan melihat tingkat signifikansi

hubungan antar variabel yang tampak dari nilai $\mathrm{P}$ dan $\mathrm{CR}$ masing-masing hubungan antar variabel. Untuk proses pengujian statistik regression weight tampak pada tabel 3. berikut ini.

Tabel 3. Regression Weights

\begin{tabular}{|c|c|c|c|c|c|}
\hline & & Estimate & S.E. & C.R. & $\mathbf{P}$ \\
\hline KAP PEM & $<--\quad$ KOM PENG PEM & 0.281 & 0.1 & 2.331 & 0.02 \\
\hline KAP PEM & $<--$ ORI KEW & 0.499 & 0.091 & 3.883 & 0 \\
\hline KIN PEM & $<-\quad$ ORI KEW & 0.353 & 0.097 & 3.268 & 0.001 \\
\hline KIN PEM & $<--\quad$ KOM PENG PEM & 0.186 & 0.099 & 1.994 & 0.046 \\
\hline KIN PEM & $<_{-} \quad$ KAP PEM & 0.555 & 0.175 & 4.027 & 0 \\
\hline $\mathrm{X} 6$ & $<-\quad$ KOM PENG PEM & 0.710 & & & \\
\hline $\mathrm{X} 5$ & $<--\quad$ KOM PENG PEM & 0.826 & 0.165 & 6.336 & 0 \\
\hline $\mathrm{X} 4$ & $<-\quad$ KOM PENG PEM & 0.661 & 0.153 & 5.286 & 0 \\
\hline $\mathrm{X} 9$ & $<--$ KAP PEM & 0.666 & & & \\
\hline $\mathrm{X} 8$ & $<-\quad$ KAP PEM & 0.681 & 0.181 & 5.694 & 0 \\
\hline $\mathrm{X} 7$ & $<--$ KAP PEM & 0.720 & 0.205 & 5.941 & 0 \\
\hline $\mathrm{X} 3$ & $<-$ ORI KEW & 0.791 & & & \\
\hline $\mathrm{X} 2$ & $<-\quad$ ORI KEW & 0.798 & 0.103 & 8.037 & 0 \\
\hline $\mathrm{XI}$ & $<--$ ORI KEW & 0.829 & 0.113 & 8.087 & 0 \\
\hline $\mathrm{XI} 1$ & $<-\quad$ KIN PEM & 0.702 & 0.112 & 7.132 & 0 \\
\hline $\mathrm{X} 12$ & $\begin{array}{ll}-- & \text { KIN PEM } \\
\end{array}$ & 0.682 & 0.108 & 6.919 & 0 \\
\hline $\mathrm{X} 10$ & $<-\quad$ KAP PEM & 0.847 & 0.184 & 7.12 & 0 \\
\hline $\mathrm{X} 13$ & $<-\quad$ KIN PEM & 0.771 & 0.108 & 8.338 & 0 \\
\hline $\mathrm{X} 14$ & $<--$ KIN PEM & 0.805 & & & \\
\hline
\end{tabular}

Sumber : data yang dikembangkan dalam penelitian ini, 2013 
Tampak dalam tabel 3. di atas bahwa keseluruhan hipotesis yang diajukan dalam penelitian ini terbukti signifikan.Variabel kapabilitas pemasaran memiliki efek positif terbesar terhadap kinerja pemasaran dengan nilai rasio kritis 4,027. Diikuti kemudian dengan efek orientasi kewirausahaan terhadap kapabilitas pemasaran dengan nilai rasio kritis 3,883 . Urutan berikutnya adalah efek positif orientasi kewirausahaan terhadap kinerja pemasaran dengan nilai rasio kritis sebesar 3.268, kemudian kompetensi pengetahuan pemasaran terhadap kapabilitas pemasaran dengan nilai rasio kritis sebesar 2.331, dan terakhir kompetensi pengetahuan pemasaran terhadap kinerja pemasaran dengan nilai rasio kritis sebesar 1.994 .

\section{Evaluasi atas Multikolinearitas dan Singularitas}

Indikasi

adanya

multikolinearitas dan singularitas determinan matriks kovarian yang benar-benar kecil, atau mendekati nol. Dari hasil pengolahan data nilai determinan matriks kovarians sampel didapatkan hasil sebagai berikut:

Determinant of Sample Covariance Matrix $=5.7345 e+004$

Melihat nilai determinan matriks kovarians sampel yang jauh dari nilai nol, maka dapat disimpulkan bahwa data penelitian ini terbebas dari multikolinearitas dan singularitas.

\section{Tahap Interpretasi dan Modifikasi Model}

Untuk menilai sebuah model penelitian sehingga dapat dikatakan baik, maka nilai Standardized Residual Covariance yang kecil harus terpenuhi. Nilai $\pm 2,58$ merupakan batas nilai Standardized Residual Covariance yang disyaratkan (Ferdinand, 2002). Hasil pengolahan data untuk analisis model penelitian tampak dalam tabel 4. di bawah ini.

Tabel 4. Standardized Residual Covariance

\begin{tabular}{|l|c|c|c|c|c|c|c|c|c|c|c|c|c|c|}
\hline & $\mathbf{X 1 4}$ & $\mathbf{X 1 3}$ & $\mathbf{X 1 0}$ & $\mathbf{X 1 2}$ & $\mathbf{X 1 1}$ & $\mathbf{X 1}$ & $\mathbf{X 2}$ & $\mathbf{X 3}$ & $\mathbf{X 7}$ & $\mathbf{X 8}$ & $\mathbf{X 9}$ & $\mathbf{X 4}$ & $\mathbf{X 5}$ & $\mathbf{X 6}$ \\
\hline $\mathrm{X} 14$ & 0 & 0.521 & 0.03 & -0.3 & - & - & - & - & 0.617 & 0.308 & 0.312 & 0.529 & - & - \\
\hline $\mathrm{X} 13$ & 0.521 & 0 & - & -0.35 & - & 0.532 & - & - & - & - & - & 1.67 & - & 0.497 \\
\hline $\mathrm{X} 10$ & 0.03 & - & 0 & 0.395 & - & - & - & - & - & 0.09 & 0.574 & 0.456 & - & 0.496 \\
\hline $\mathrm{X} 12$ & -0.3 & -0.35 & 0.395 & 0 & 0.401 & - & - & 0.335 & 0.764 & 0.463 & - & 1.678 & 0.024 & - \\
\hline $\mathrm{X} 11$ & - & - & - & 0.401 & 0 & 1.048 & 0.738 & 0.325 & 0.217 & - & - & 0.731 & - & 0.683 \\
\hline $\mathrm{X} 1$ & - & 0.532 & - & - & 1.048 & 0 & 0.043 & - & 0.373 & 0.243 & - & 1.025 & -0.69 & 0.799 \\
\hline $\mathrm{X} 2$ & - & - & - & - & 0.738 & 0.043 & 0 & 0.082 & 0.626 & 0.445 & 0.592 & 1.035 & - & - \\
\hline $\mathrm{X} 3$ & - & - & - & 0.335 & 0.325 & - & 0.082 & 0 & 0.71 & 0.032 & 0.099 & 1.28 & - & 0.522 \\
\hline $\mathrm{X} 7$ & 0.617 & - & - & 0.764 & 0.217 & 0.373 & 0.626 & 0.71 & 0 & 0.416 & - & - & - & 0.349 \\
\hline $\mathrm{X} 8$ & 0.308 & - & 0.09 & 0.463 & - & 0.243 & 0.445 & 0.032 & 0.416 & 0 & - & 0.783 & - & 0.499 \\
\hline $\mathrm{X} 9$ & 0.312 & - & 0.574 & - & - & - & 0.592 & 0.099 & - & - & 0 & 0.929 & - & 0.565 \\
\hline $\mathrm{X} 4$ & 0.529 & 1.67 & 0.456 & 1.678 & 0.731 & 1.025 & 1.035 & 1.28 & - & 0.783 & 0.929 & 0 & 0.048 & - \\
\hline $\mathrm{X} 5$ & - & - & - & 0.024 & - & -0.69 & - & - & - & - & - & 0.048 & 0 & 0.232 \\
\hline $\mathrm{X} 6$ & -0.521 & 0.497 & 0.496 & - & 0.683 & 0.799 & - & 0.522 & 0.349 & 0.499 & 0.565 & - & 0.232 & 0 \\
\hline
\end{tabular}

Sumber : data yang dikembangkan dalam penelitian ini, 2013 


\section{Uji Reliabilitas dan Variance}

\section{Extract}

Penilaian unidimensionalitas dan reliabilitas dilakukan untuk mengetahui apakah suatu indikator memiliki derajat kesesuaian yang baik dalam menerangkan satu dimensi dalam sebuah model.Unidimensionalitas sendiri merupakan asumsi yang digunakan dalam menghitung reliabilitas.Reliabilitas adalah ukuran konsistensi dari indikator dalam mengindikasikan sebuah konstruk. Ada dua cara yang dapat digunakan, yaitu dengan melihat construct reliability dan variance extracted. Nilai cut of value-nya masing-masing adalah 0,70 dan 0,50 .

\section{Pengujian Hipotesis}

Pengujian hipotesis ini didasarkan pada hasil pengolahan data penelitian dengan menggunakan analisis SEM. Secara umum, pengujian hipotesis ini dilakukan dengan menganalisis nilai $\mathrm{CR}$ dan nilai $\mathrm{P}$ hasil olah data dibandingkan dengan batasan statistik yang disyaratkan, yakni di atas $\pm 1,96$ untuk nilai $\mathrm{CR}$ dan di bawah 0,05 untuk nilai $P$. Jika hasil olah data memenuhi persyaratan tersebut, maka hipotesis penelitian yang diajukan dapat dinyatakan diterima.

Pengujian hipotesis penelitian dikupas secara terinci dan bertahap sesuai dengan urutan hipotesis yang diajukan. Pada penelitian ini, lima hipotesis diajukan dan pembahasannya adalah sebagai berikut :

\section{Uji Hipotesis 1}

Hipotesis pertama dalam penelitian ini adalah orientasi kewirausahaan berpengaruh positif terhadap kapabilitas pemasaran.Dari hasil olah data diketahui bahwa nilai CR pada hubungan antara variabel orientasi kewirausahaan dan variabel kapabilitas pemasaran seperti yang tampak pada tabel 4. adalah sebesar 3.883 , dengan nilai $\mathrm{P}$ sebesar 0 (nol). Kedua nilai ini menunjukkan hasil yang memenuhi syarat, yaitu di atas 1,96 untuk CR dan di bawah 0,05 untuk P. Oleh karena itu dapat disimpulkan bahwa hipotesis pertama terbukti signifikan secara statistik.

\section{Uji Hipotesis 2}

Hipotesis kedua dalam penelitian ini adalah kompetensi pengetahuan pasar berpengaruh posiif terhadap kapabilitas pemasaran.Dari hasil olah data diketahui bahwa nilai CR pada hubungan antara variabel kompetensi pengetahuan pasar dan variabel kapabilitas pemasaran seperti yang tampak pada tabel 4. adalah sebesar 2.331, dengan nilai $\mathrm{P}$ sebesar 0.02 . Kedua nilai ini menunjukkan hasil yang memenuhi syarat, yaitu di atas 1,96 untuk CR dan di bawah 0,05 untuk P. Oleh karena itu dapat disimpulkan bahwa hipotesis kedua terbukti signifikan secara statistik.

\section{Uji Hipotesis 3}

Hipotesis ketiga dalam penelitian ini orientasi kewirausahaan berpengaruh positif terhadap kinerja pemasaran.Dari hasil olah data diketahui bahwa nilai $\mathrm{CR}$ pada hubungan antara variabel orientasi kewirausahaan dan variabel kinerja pemasaran seperti yang tampak pada tabel 4. adalah sebesar 3.268, dengan nilai $\mathrm{P}$ sebesar 0,001 . Kedua nilai ini menunjukkan hasil yang memenuhi syarat, yaitu di atas 1,96 untuk CR dan di bawah 0,05 untuk P. Oleh 
karena itu dapat disimpulkan bahwa hipotesis ketiga terbukti signifikan secara statistik.

\section{Uji Hipotesis 4}

Hipotesis keempat dalam penelitian ini, kompetensi pengetahuan pemasaran berpengaruh positif terhadap kinerja pemasaran. Dari hasil olah data diketahui bahwa nilai CR pada hubungan antara variabel kompetensi pengetahuan pemasaran dan variabel kinerja pemasaran seperti yang tampak pada tabel 4. adalah sebesar 1.994, dengan nilai $\mathrm{P}$ sebesar 0.046 . Kedua nilai ini menunjukkan hasil yang memenuhi syarat, yaitu di atas 1,96 untuk CR dan di bawah 0,05 untuk P. Oleh karena itu dapat disimpulkan bahwa hipotesis keempat terbukti signifikan secara statistik.

\section{Uji Hipotesis 5}

Hipotesis kelima dalam penelitian ini, kapabilitas pemasaran berpengaruh positif terhadap kinerja pemasaran.Dari hasil olah data diketahui bahwa nilai $\mathrm{CR}$ pada hubungan antara variabel kapabilitas pemasaran dan variabel kinerja pemasaran seperti yang tampak pada tabel 4. adalah sebesar 4.027, dengan nilai $\mathrm{P}$ sebesar 0 (nol). Kedua nilai ini menunjukkan hasil yang memenuhi syarat, yaitu di atas 1,96 untuk CR dan di bawah 0,05 untuk P. Oleh karena itu dapat disimpulkan bahwa hipotesis kelima terbukti signifikan secara statistik.

\section{Analisis Pengaruh}

Analisis pengaruh diperlukan untuk mengetahui besar pengaruh variabel eksogen terhadap variabel endogen baik secara langsung maupun secara tidak langsung. Besar pengaruh masing-masing variabel eksogen terhadap variabel endogen secara langsung, kemudian pengaruh secara tidak langsung dan pengaruh total tampak pada tabel 5 .

Tabel 5. Estimasi Pengaruh Total

\begin{tabular}{|l|c|c|c|c|}
\hline & ORI KEW & $\begin{array}{c}\text { KOM PENG } \\
\text { DNa }\end{array}$ & KAP PEM & KIN PEM \\
\hline KAP & 0.499 & 0.281 & 0 & 0 \\
\hline KIN & 0.63 & 0.342 & 0.555 & 0 \\
\hline X14 & 0.507 & 0.275 & 0.447 & 0.805 \\
\hline X13 & 0.485 & 0.263 & 0.428 & 0.771 \\
\hline X10 & 0.423 & 0.238 & 0.847 & 0 \\
\hline X12 & 0.429 & 0.233 & 0.379 & 0.682 \\
\hline XI1 & 0.442 & 0.24 & 0.39 & 0.702 \\
\hline XI & 0.829 & 0 & 0 & 0 \\
\hline X2 & 0.798 & 0 & 0 & 0 \\
\hline X3 & 0.791 & 0 & 0 & 0 \\
\hline$X 7$ & 0.359 & 0.202 & 0.72 & 0 \\
\hline$X 8$ & 0.34 & 0.191 & 0.681 & 0 \\
\hline$X 9$ & 0.332 & 0.187 & 0.666 & 0 \\
\hline$X 4$ & 0 & 0.661 & 0 & 0 \\
\hline$X 5$ & 0 & 0.826 & 0 & 0 \\
\hline$X 6$ & 0 & 0.71 & 0 & 0 \\
\hline
\end{tabular}

Sumber : data yang dikembangkan dalam penelitian ini 
Tabel di atas menunjukkan pengaruh total dari masing-masing konstruk terhadap konstruk tertentu. Angka yang tertera di atas merupakan akumulasi besarnya pengaruh langsung dan tidak langsung. Dengan kalimat lain, tabel 5. merupakan akumulasi pengaruh langsung dan tidak langsung sekaligus.

\section{PENUTUP}

Latar belakang dan perumusan masalah dalam penelitian ini adalah bagaimana pengaruh orientasi kewirausahaan, kompetensi pengetahuan pasar serta kapabilitas pemasaran di dalam suatu perusahaan pakaian jadi yang berskala kecil agar dapat tercapai kinerja pemasaran yang lebih tinggi sebagai usaha untuk dapat merebut pasar yang lebih luas.

\section{Kesimpulan atas Pengujian Setiap Hipotesis}

Secara umum penelitian ini telah terbukti memberikan dukungan yang signifikan terhadap konsep maupun temuan hasil penelitian terdahulu yang menyatakan bahwa orientasi kewirausahaan dan kompetensi pengetahuan pemasaran merupakan faktor penting bagi perusahaan untuk meningkatkan kapabilitas pemasaran yang kemudian membentuk satu kekuatan integral pencapaian kinerja pemasaran yang optimal.Meski kedua faktor tersebut juga memberikan efek positif yang signifikan secara langsung terhadap kinerja pemasaran, namun dalam penelitian ini direkomendasikan hubungan yang bertingkat melalui peningkatan kapabilitas pemasaran sebagai sebuah upaya strategis yang lebih optimal.
Seperti yang telah diuraikan pada bab-bab sebelumnya, terdapat lima hipotesis yang diajukan dalam penelitian ini dan dari hasil analisis telah terbukti bahwa kelima hipotesis itu signifikan, yang berarti bahwa hipotesis tersebut

merupakan rangkaian jawaban atas pertanyaan penelitian yang diajukan di dalam penelitian ini. Dengan demikian, berikut ini diuraikan secara detil kesimpulan deskriptif hasil penelitian ini, yaitu :

\section{Kesimpulan atas Masalah Penelitian}

Hasil Penelitian ini membuktikan signifikansi pengaruh di antara keseluruhan variabelvariabel dalam penelitian ini.Orientasi kewirausahaan dan kompetensi pengetahuan pemasaran memberikan efek positif secara signifikan baik langsung terhadap kinerja pemasaran maupun melalui kapabilitas pemasaran. Kapabilitas pemasaran menjadi variabel paling dominan dalam proses meningkatkan kinerja pemasaran, terutama yang diantesedeni orientasi kewirausahaan.

Uraian tersebut di atas telah menjawab sekaligus mengkonfirmasi permasalahan penelitian yang muncul dari telaah hasil temuan Tsai\&Shih (2004) , Menon et al (1999) dan Weerawardena (2003), di mana kapabilitas pemasaran menjadi kunci penting upaya peningkatan kinerja pemasaran. Jika Tsai\&Shih (2004) tidak menemukan signifikansi pengaruh langsung kompetensi pengetahuna pemasaran tanpa melalui kapabilitas pemasaran, maka penelitian ini telah menemukan fakta yang berbeda.Hasil penelitian ini mendukung temuan Glazer (1991), 
Hamel dan Prahalad (1994), Sinkula (1994), serta Fahey \& Smithee (1999).

\section{Implikasi Manajerial}

Hasil penelitian dan implikasi teoritis di atas, untuk selanjutnya dikembangkan menjadi sebuah dasar formulasi strategi dan menjadi bentuk upaya meningkatkan kinerja pemasaran untuk perusahaanperusahaan dalam industri pakaian jadi khususnya, dan perusahaan dalam industri lain yang memiliki kesamaan kondisi dan fakta persaingan pemasaran di industri garmen. Manajer di setiap perusahaan seyogyanya memperhatikan faktorfaktor yang dapat mempengaruhi kinerja pemasaran, seperti konten penelitian ini, yakni orientasi kewirausahaan, kompetensi pengetahuan pemasaran, dan kapabilitas pemasaran.

\section{DAFTAR PUSTAKA}

Achrol, Ravi, (1991), Evaluation of the Marketing Organization : New Form For Turbulence Environment, Journal Marketing

Act, Zoltan and David Audretsch,(1987), Inovation, Market Structur, and firm Size, Reviuw Of Economic and Statistics.

Adnand.N. Garden, H.K., Morris, T., 2007, Knowlledge-based innovation: emergence and embandding or new practice areas in management consulting firms. Academy of management journal 50 (2), 406-428

Agarwal, S., Erramilli, M.K. and Dev, C.S. (2003) Market orientation and performance in service firms:role of innovation. Journal of Services Marketing 17, 1, 68-82.

AhgalyaSubbiah and Othman IbrahimE-government towards service co-creation of value African Journal of Business Management Vol. 5(22), pp. 9401-9411, 30 September, 2011

Aliaga, O Alfredo,(2005), A study of inovative Human Resources Development Practise in Minnesota Companies, Ph.D dissertation Univesity of Minnesota.

Alesina, A., R. Baqir, and W Easterly.(1997). "Public Goods and Ethnic Divsions," Quarterly Journal ofEconomics 114, 1243-1284.

Baker William E. And Sinkula, James. M (1999) Learning Orientation, Market Orientation, and Inovation : Itegrating and Exstending Models of Organizational Pervormence, Journal matrket Focused Management Vpl 4 No, 4. Pp. 295-308

Baker, W. E., \& Sinkula, J. M. (1999).The synergistic effect of market orientation andlearning orientation.Journal of the Academy of Marketing Science, 27(4), 411-27

Bamshad, Michael et al. 2001. "Genetic Evidence on the Origins of Indian Caste Populations."Genome Research 11, 6: 994-1004.

Barney J.B, (1991) Firm Resources and sustained Competitive Advantage Journal of management 
Bates, R. (1983)."Modernization, Ethnic Competition, and the Rationality of Politics in Contemporary Africa."In D. Rothchild, and V. A. Olunsorola (eds), State versus Ethnic Claims: African Policy Dilemmas,

Beverland, M. \& Lindgreen, A. (2007) Implementing market orientation in industrial firms: a multiple case study. Industrial Marketing Management Vol. 36, No. 4, 430-442.

Bhuiana, S. N., Menguc, B., \& Bell, S. (2005). Just entrepreneurial enough: the moderating effect of entrepreneurship on the relationship between market orientation and performance. Journal of Business Research, 58(1), 9-17.

Child, John, and Rita Gunter McGrath, 2001, "OrganizationUnfettered:Org anizational Form in an Information - Intensive Economy", Academy of Management Journal, Vo. 44, No. 6, p. 1135-1148

Cooper, Juett R., 1998, “A Multidimensional Approach to the Adoption of Innovation", Management Decision, Vol. 36, p. 493-502

Dharmmesta, Basuswasta, 1993, "Perilaku Belanja Konsumen Era 90-an dan Strategi Pemasaran", Jurnal Ekonomi dan Bisnis, No. 1, Vol VIII

Ferdinand, A.T, 2000,“ Manajemen Pemasaran: Suatu Pendekatan Stratejik", ProgramMM UNDIP,Semarang
Joewono, Hadi. Handito, 2005, "7 in 1 StrategyTowardGlobalCompe titiveness", Arrbey

Kaban, Bakti Karya, 2002, "Total Customer Experience Sebagai Jalan Mencapai Perusahaan Kelas Dunia", Manajemen, Desember 2002, hal. 18-19

Keefe, Lisa M , 2004, "What Is The Meaning of Marketing?", Marketing News, Sept Chicago II : American Marketing Association

Khurana, Anil, Stephen R Rosenthal, 1997, "Integrating the Fuzzy Front End of New Product Development", Sloan Management Review, Winter, p. $103-120$

Kotler, Philip, 2005 ,Manajemen Pemasaran: Analisis, Perencanaan, Implementasi dan Pengendalian, Jilid 1, Erlangga, Jakarta , Manajemen Pemasaran:

Analisis, Perencanaan, Implementasi dan Pengendalian, Jilid 2, Erlangga, Jakarta

Lado, Augustine A, Nancy G Boyd, peter Wright, 1993, “A Competency-Based Model of Sustainable Competitive Advantage: Toward a Conceptual Integration", Journal of Management, Vol. 18 , No. 1, p. 77-91

Li, Tiger, Roger J Calantone, 1998, "The Impact of Market Knowledge Competence on New Product Advantage: Conceptualization and Empirical Examination", Journal of Marketing, Vol. 62, Oktober, p. 13-29 
Lukas A. Bryan and Ferrel C.O, 2000, "The Effect of Marketing Orientation on Product Innovation", Journal of the Academy of Marketing Science, Vol. 28, No. 2, p. 239-247

Masson, Geof, Bart van Ark, Karin Wagner, 1994, "Productivity, Product Quality and Workforce Skills: Food Processing in Four European Countries", National Institute Economic Review, February, p. $62-83$

Menon, Ajay., Bernard J. Jaworski, and Ajay K. Kholi, 1997, "Product Quality: Impact of Interdepartmental Interactions", Journal of The Academy of Marketing Science, Vol. 25, No. 3, p. 187-200

Munadi, Imam, 2001, "Rethinking the Marketing", Manajemen, Jakarta

Narver, J. C., Slater, S. F., MacLachlan, D. L.,

Responsive and Proactive Market Orientation and NewProduct Success, Journal of Product Innovation

Management, vol. 21, 2004, p. 334-347.

Nenonen and KajStorbackaBusiness model design: conceptualizing networked value cocreationThe 2009 Naples Forum on Services:ServiceDominant Logic, Service Science, and Network Theory

Noble, C. H., Sinha, R. K., \& Kumar, A. (2002). Market Orientation and Alternative Strategic
Orientations: A Longitudinal Assessment of Performance Implications.Journal of Marketing, 66(4), 25-40.

Olson, Eric M., Orville C. Walker Jr., and Robert W. Ruekert, 1995, "Organizational for Effective New Product Development: The Moderating Role of Product Innovativeness", Journal of Marketing, Vol. 59 (January), P. 48-62

Song, Anne P. Massey and Mitzi M. Montoya Weiss, 2001, "Getting It Together: Temporal Coordination and Conflict Management in Global Virtual Teams", Academy of Management Journal, Vo. 44, No. 4, p. 6180

Voss, Glenn B., and Zannie Giraud Voss, 2000, "Strategic Orientation and Firm Performance in an Artistic Environment", Journal of Marketing, Vol. 64, (January), p. $67-83$

Wind, Jerry., and Vijay Mahajan, 1997, "Issue and Opportunities in New Product Development: An Introduction to the Special Issue", Journal of Marketing Science, Vol. XXXIV, p. 1-12

Yoo, Boonghee., Naveen Donthu., and Sungho Lee., 2000, "An Examination of Selected Marketing mIx Element and Brand Equity", Journal of Academy of Marketing Science, Vol. 28, No. 2, p. 195-211 